\title{
Assessment of eating disorders among early adolescents (10 - 15 years)
}

\author{
Aplaa A Abd El-hafeez ${ }^{1}$, Hoda D Fahmy ${ }^{2}$, Hend S Mohammed ${ }^{3}$. \\ 1. Teacher at Technical Secondary Nursing School in Diarout City, Egypt. \\ 2. Professor of Community Health Nursing, Faculty of Nursing, Assiut University, Egypt. \\ 3. Lecturer of Pediatric Nursing, Faculty of Nursing, Assiut University, Egypt.
}

\begin{abstract}
Introduction: Eating disorders are complex illnesses that affect people of all ages; the onset of eating disorders typically occurs during pre-adolescence or adolescence. Aim of the study: to assess eating disorders among early adolescents (10-15years). Subjects and method: Design: Cross sectional descriptive design was utilized in this study. Setting: The study was conducted at all primary and preparatory schools in Dairout city, then selected randomly $10 \%$ from the total number of students in each preparatory schools as well as fifth and sixth grade of primary schools. Sample: The total number of sample are 843 students were included in this study. Tools: Two tools were used for this study. Eating habits questionnaire to assess adolescents eating habits and Body Mass Index (BMI) scale to assess body-weight and healthy body image. Results: findings in this study, cleared that more than half $(53.0 \%)$ of the studied sample had eating disorders, $54.1 \%$ of them had anorexia and $45.9 \%$ of them had bulimia. Conclusion: Eating disorders have high prevalence among early adolescents, that characterized by a disturbance in eating habits and behavior. Recommendation: education program for preadolescents about eating disorders to increase their awareness.
\end{abstract}

\section{Keywords: Assessment, Eating Disorders \& Early Adolescent.}

\section{Introduction}

The period of adolescence is one of intense change which can bring with it a great deal of stress, confusion and anxiety for many. The physical transformation that takes place during this time is enormous and often intertwined with feelings of selfconsciousness, low self esteem and comparison with peers.( Rosen, 2014)

Adolescence is a time where many big changes take place in a seemingly short period of time whereby a person may feel tremendous pressure to find their place in the world despite a great deal of confusion, and a sense of feeling ill-equipped or welcome to the plethora of changes around them( Pearson, et al., 2010)

Although eating disorders are usually a result of a number of personal, environmental, psychological, biological and social factors, it seems that adolescents are the most at-risk group of people in developing an eating disorder, and this is due to a number of factors.( Melbye\& Hansen, H, 2015).

Eating disorders describe illnesses that are characterized by irregular eating habits and severe distress or concern about body weight or shape. Eating disturbances may include inadequate or excessive food intake which can ultimately damage an individual's well-being (Abebe, et al., 2012).

The two most prominent eating disorders, anorexia nervosa and bulimia nervosa, have been

identified in all age groups and both sexes, although $90 \%$ of cases are females and are most prevalent among adolescents (Tholking, et al., 2011)
The greatest risk factors for eating disorders include a disturbance in body image over-controlled or undercontrolled eating, and lastly, taking extreme measures in order to control one's weight or shape. ( Baker, et al., 2012)

Eating disorders result from a complicated interaction of biological, psychological, and social factors. There is no clear cause of eating disorders, but they can be a result of many things (Onozaka, et al., 2014)

Eating disorders can have lifelong effects on person health. They have long and short term effects. Examples of short term effects are malnutrition, dehydration, electrolyte imbalances, edema, dry hair and skin, bruising or swelling and hyperactivity. These are only a few of many short term effects of this life threatening disorder. Long term effects include hypotension or hypertension, thrombocytopenia, diabetes, osteoporosis, kidney or liver infection and failure, amenorrhea, slowed heart rate, paralysis, and eventually death.(combs,et al., 2013).

Therefore, prevention should not directly be associated with eating disorders, but with having a healthy lifestyle and accepting all people no matter what size they are. Since eating disorders usually develop in adolescents and children, schools can help prevent eating disorders. (Allen, et al., 2012)

Teachers and school councilors should have a general knowledge on eating disorders. Schools can also help with prevention of eating disorders by holding after school support groups. These support groups should encourage healthy lifestyle and eating habits, but not 
dieting. These groups should also empower adolescents to feel good about their bodies no matter what size they are and also give adolescents a place where they can talk about the pressures to be thin that comes from peers and the media.( Duluth,2010)

It is essential to nurses to observe students' nutritional status as eating disorders can be life threatening. It is also important to ensure they maintain adequate nutrition and electrolyte balance. If an eating disorder has been identified, the nurse must monitor weight on a regular basis. (Cano et al., 2012).

This can be achieved by encouraging the supervision of patients during and after mealtimes in order to prevent vomiting after eating. Setting time limits for each meal will help to set realistic expectations and encourage a relaxed atmosphere at mealtimes that will, in turn, help to reduce stress and anxiety. (Hart et al., 2011)

\section{Significance of the study}

Nearly one in four (22\%) Egyptians is an adolescent (ages 10-19) and young adults as a whole (ages 1024) make up about one-third of the population just over 20 million persons. According to study is applied on Egyptian schools; about $45.2 \%$ from students have eating disorders.(Taha\&Marawan,2015). This is the first study in this geographical location which will be identifying eating disorders among early adolescents.

\section{Aim of the study}

The aim of this study was to assess eating disorders among early adolescents (10-15years).

\section{Research Question}

The following research question was determined:

- What are eating disorders among early adolescents?

- What are adolescents' eating habits?

- Does the early adolescents aware about eating disorders?

\section{Subjects \& Method \\ Research design:}

Cross sectional descriptive design was being utilized in this study.

\section{Setting:}

The study was conducted at all primary and preparatory schools in Dairout city at Assiut government, which selected by random sample.

\section{Sample}

The study subject included a convenient sample of primary and preparatory schools. The number of preparatory schools at Dairout city are 10, and primary schools are 15 , then selected randomly $10 \%$ from the total number of students in each preparatory schools as well as fifth and sixth grade of primary schools. The total number of sample are 843 students.

Tools of the study

Tools were used for collecting data of study, it was developed by researchers to collect the required data that included two parts.

Tool (1): Self-administered questionnaire: its divided into (2) parts:

Part (1): It included questions regarding personal data such as (name, sex, age,...etc), as well as questions to assess adolescent's knowledge about eating disorders such as definition, types , and complications, ....etc.

Part (2):Eating habits questionnaire: it designed to measure the student's eating habits .This questions was developed by (Gunes,et al.,2012),(Doyle, 2011), (Hardman\& Richards, 2001), modified and translated to Arabic language by the researchers. Eating habits questionnaire: It is a likert like scale with four options that representing how often participants practiced eating habits with four options; (4=Often- 3=Sometimes- 2=Rarely- 1=Never). It consisted of two parts:

Part I: criteria of bulimia, Included 15 item of unhealthy eating habits that scored from 60. Scores of the studied participants are classified as the following:

- Scores ranged from 15 to 30 indicated neutral eating habits (means that eating habits are healthy).

- Scores ranged from 31 to 60 indicated bulimia.

Part II: criteria of anorexia, Included 23 item of unhealthy eating habits that scored from 92 . Scores of the studied participants are classified as the following:

- Scores ranged from 23 to 46 indicated neutral eating habits (means that eating habits are healthy).

- Scores ranged from 47 to 92 indicated anorexia.

The total scores of eating habits questionnaire are 152 scores. Scores of the study participants are classified as the following:

- Scores ranged from 152 to 77 indicated unhealthy eating habits.

- Scores ranged from 76 to 38 indicated neutral eating habits (means that eating habits are healthy).

Tool (2): Body Mass Index (BMI) scale: It was used to assess body-weight and healthy body image. Body mass index (BMI) calculated according to (WHO, 2017), as ratio between weight in kilograms and height in meters squared and results recorded as $(\mathrm{kg} / \mathrm{m} 2)$. Participants categorized according to their Body Mass Index as the following: 
Under weight: BMI is lower than $18.5 \mathrm{~kg} / \mathrm{m} 2$

Normal weight: BMI ranged from 18.5 to $24.9 \mathrm{~kg} / \mathrm{m} 2$

Over weight: BMI ranged from 25 to $29.9 \mathrm{~kg} / \mathrm{m} 2$

Obese : BMI is more than $30 \mathrm{~kg} / \mathrm{m} 2$

\section{Reliability}

Internal consistency for tool I (part two) were calculated using Cronbach's Alpha coefficient test and proved to be reliable $(\alpha=(0.7)$.

\section{Validity}

The tools were reviewed by jury (5 nursing experts) after translation from English to Arabic version to test validity of it.

\section{Pilot study}

Pilot study was done on $10 \%$ of students(84 students) to evaluate the clarity and understanding of the tools. It also helped in the estimation of the time needed to fill the form. The student who was tested in the pilot study was included in the main study sample.

\section{Administrative design:}

A written permission will be obtained from Dean of the Faculty of Nursing, Assuit University to the Ministry of Education; this letter will include a brief explanation of the objective of the study and permission to carry out the study.

\section{Fieldwork}

- Before conducted the study an official permission was obtained from the Dean of the faculty of nursing to proceed with study.

- The researcher introduced herself to the student and briefly explained the nature of the study.

- Formal consent was obtained from student orally before being involved in the study after explanation of the nature and purpose of the study and there are no risks or cost in participation, and there are voluntary participation and confidentiality of each subject who agrees to participate and to fill the questionnaire.

- Data collected by the researcher through selfadministrating questionnaire to the students in classroom (each academic year alone).

- The filling of questionnaire took 10-15 minutes.

- The researcher collected the sample through three days, per week.

- The data collection took about four months (April, May, September and October 2016).

\section{Ethical considerations}

- Research proposal was being approved from ethical committee in the Faculty of Nursing, Assiut University.

- There is no risk for study subjects during application of the research.

- The study was following common ethical principles in clinical research.
-Written consent will be obtained from adolescents that are willing to participate in the study after explaining the nature and purpose of the study.

- Confidentiality and anonymity was being assured.

- Study subjects have the right to refuse to participate or withdraw from the study without any rational at any time.

- Study subjects privacy was being considered during collection of the data.

\section{Statistical analysis}

Data were analyzed using the statistical package for social science (SPSS) version 11.5 (Windows Microsoft). Continuous data were expressed as percentage; mean and SD. discrete data were expressed as percentage. Comparison between variables was done using chi-square test. Probability (p-value) less than 0.05 was considered significant. 


\section{Results}

Table (1): Distribution of studied adolescents according to their personal data. $(n=843)$.

\begin{tabular}{|l|c|c|}
\hline \multicolumn{1}{|c|}{ Items } & \multicolumn{2}{c|}{ No. } \\
\hline Age & \multicolumn{2}{c|}{} \\
\hline Range & $11-15$ & 47.9 \\
\hline Age group & \multicolumn{2}{c|}{} \\
\hline $11-13$ years & 452 & 53.6 \\
\hline $13-15$ years & 391 & 46.4 \\
\hline Mean SD & \multicolumn{2}{c|}{$13.3 \pm 1.4$} \\
\hline Sex & \multicolumn{2}{c|}{} \\
\hline Male & 404 & 47.9 \\
\hline Female & 439 & 52.1 \\
\hline Grade & & \\
\hline primary (fifth grade) & 123 & 14.6 \\
\hline primary (sixth grade) & 135 & 16.0 \\
\hline Preparatory (first grade) & 193 & 22.9 \\
\hline Preparatory (second grade) & 186 & 22.1 \\
\hline Preparatory (third grade) & 206 & 24.4 \\
\hline Birth order & & \\
\hline First & 251 & 29.7 \\
\hline Second & 166 & 19.7 \\
\hline Third & 175 & 20.8 \\
\hline Fourth & 102 & 12.1 \\
\hline Fifth & 94 & 11.2 \\
\hline more than fifth & 55 & 6.5 \\
\hline
\end{tabular}

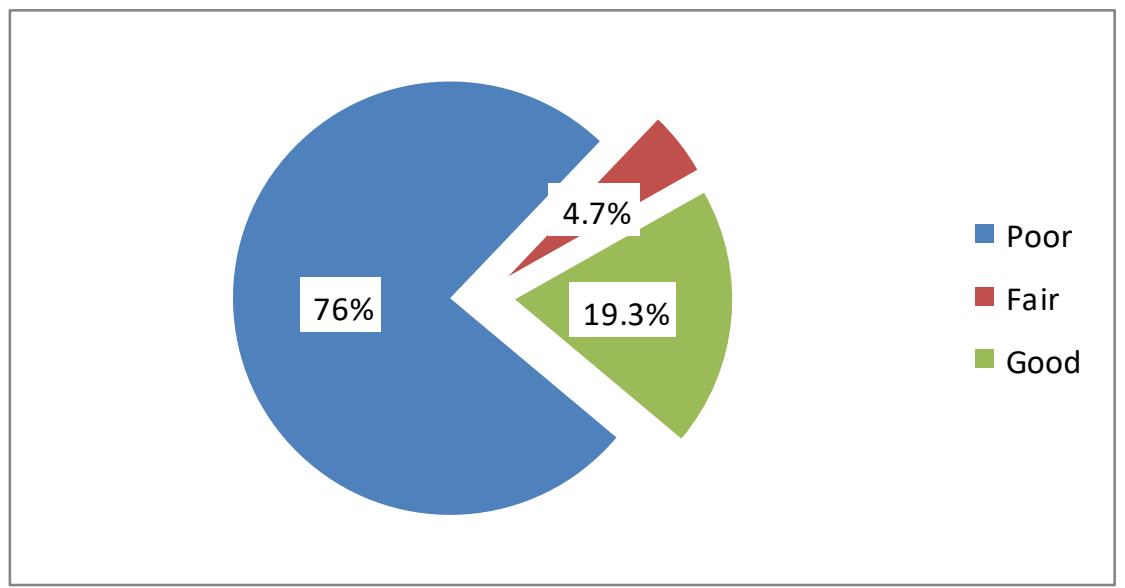

Fig (1): Total score of knowledge among studied adolescents about eating disorders.

Table(2): Distribution of eating disorders among studied adolescents $(\mathrm{n}=\mathbf{8 4 3})$.

\begin{tabular}{|l|c|c|}
\hline \multicolumn{1}{|c|}{ Items } & No. & \% \\
\hline Normal eating habits & 396 & 47.0 \\
\hline Eating disorders & 447 & 53.0 \\
\hline Types of eating disorders $\mathbf{n = 4 4 7}$ & 205 & 45.9 \\
\hline Bulimia & 242 & 54.1 \\
\hline Anorexia & \multicolumn{2}{|c|}{} \\
\hline
\end{tabular}


Table (3): Distribution of Body mass index among studied adolescents $(n=843)$.

\begin{tabular}{|l|c|c|}
\hline \multicolumn{1}{|c|}{ Body mass index } & NO. & \% \\
\hline Underweight & 312 & 37.0 \\
\hline Normal & 449 & 53.2 \\
\hline Overweight & 52 & 6.2 \\
\hline Obese & 30 & 3.6 \\
\hline
\end{tabular}

Table (4): Relation between total score of knowledge among studied adolescents and their personal data $(\mathrm{n}=$ 843).

\begin{tabular}{|c|c|c|c|c|c|c|c|c|}
\hline \multirow{3}{*}{ Items } & \multicolumn{6}{|c|}{ Knowledge level } & \multirow{3}{*}{$\mathbf{X}^{2}$} & \multirow{4}{*}{ P. value } \\
\hline & \multicolumn{2}{|c|}{ Poor $(n=641)$} & \multicolumn{2}{|c|}{ Fair $(n=40)$} & \multicolumn{2}{|c|}{$\operatorname{Good}(n=162)$} & & \\
\hline & No. & $\%$ & No. & $\%$ & No. & $\%$ & & \\
\hline \multicolumn{8}{|l|}{ Age } & \\
\hline Mean \pm SD & \multicolumn{2}{|c|}{$13 \pm 1.4$} & \multicolumn{2}{|c|}{$14.4 \pm 0.7$} & \multicolumn{2}{|c|}{$14.1 \pm 0.9$} & \multirow[t]{2}{*}{$\mathrm{F}=66.889$} & \multirow{2}{*}{$0.000 * *$} \\
\hline Range & \multicolumn{2}{|c|}{$11-15$} & \multicolumn{2}{|c|}{$13-15$} & \multicolumn{2}{|c|}{$13-15$} & & \\
\hline \multicolumn{9}{|l|}{ Sex } \\
\hline Male & 275 & 42.9 & 22 & 55 & 107 & 66 & \multirow{2}{*}{28.606} & \multirow{2}{*}{$0.000 * *$} \\
\hline Female & 366 & 57.1 & 18 & 45 & 55 & 34 & & \\
\hline \multicolumn{9}{|l|}{ Grade } \\
\hline $\begin{array}{l}\text { Primary (fifth } \\
\text { grade) }\end{array}$ & 123 & 19.2 & 0 & 0 & 0 & 0 & \multirow{5}{*}{163.187} & \multirow{5}{*}{$0.000 * *$} \\
\hline $\begin{array}{l}\text { Primary (sixth } \\
\text { grade) }\end{array}$ & 135 & 21.1 & 0 & 0 & 0 & 0 & & \\
\hline $\begin{array}{l}\text { Preparatory (first } \\
\text { grade) }\end{array}$ & 132 & 20.6 & 4 & 10 & 57 & 35.2 & & \\
\hline $\begin{array}{l}\text { Preparatory } \\
\text { (second grade) }\end{array}$ & 140 & 21.8 & 18 & 45 & 28 & 17.3 & & \\
\hline $\begin{array}{l}\text { Preparatory (third } \\
\text { grade) }\end{array}$ & 111 & 17.3 & 18 & 45 & 77 & 47.5 & & \\
\hline \multicolumn{9}{|l|}{ Birth order } \\
\hline Premier & 177 & 27.6 & 9 & 22.5 & 65 & 40.1 & \multirow{6}{*}{47.514} & \multirow{6}{*}{$0.000 * *$} \\
\hline Second & 108 & 16.8 & 6 & 15 & 52 & 32.1 & & \\
\hline Third & 149 & 23.2 & 8 & 20 & 18 & 11.1 & & \\
\hline Fourth & 86 & 13.4 & 5 & 12.5 & 11 & 6.8 & & \\
\hline Fifth & 75 & 11.7 & 7 & 17.5 & 12 & 7.4 & & \\
\hline More than fifth & 46 & 7.2 & 5 & 12.5 & 4 & 2.5 & & \\
\hline \multicolumn{9}{|l|}{ practice sport } \\
\hline Yes & 236 & 36.8 & 27 & 67.5 & 104 & 64.2 & \multirow{2}{*}{49.248} & \multirow{2}{*}{$0.000 * *$} \\
\hline No & 405 & 63.2 & 13 & 32.5 & 58 & 35.8 & & \\
\hline
\end{tabular}

** Mean there is statistically significant difference 
Table (5): Relation between types of eating disorders among studied adolescents and their personal data. $(\mathrm{n}=$ 843).

\begin{tabular}{|c|c|c|c|c|c|c|c|c|}
\hline \multirow{3}{*}{ Items } & \multicolumn{6}{|c|}{ Eating disorders } & \multirow{3}{*}{$\mathbf{X}^{2}$} & \multirow{3}{*}{ P. value } \\
\hline & \multicolumn{2}{|c|}{ Bulimia $(n=205)$} & \multicolumn{2}{|c|}{$\begin{array}{c}\text { Anorexia } \\
(n=242)\end{array}$} & \multicolumn{2}{|c|}{ Normal $(n=396)$} & & \\
\hline & No. & $\%$ & No. & $\%$ & No. & $\%$ & & \\
\hline \multicolumn{9}{|l|}{ Age } \\
\hline Mean \pm SD & \multicolumn{2}{|c|}{$13.9 \pm 1.1$} & \multicolumn{2}{|c|}{$13.6 \pm 1.4$} & \multicolumn{2}{|c|}{$12.7 \pm 1.3$} & \multirow{3}{*}{$\mathrm{F}=75.419$} & \multirow{2}{*}{$0.000 * *$} \\
\hline Range & \multicolumn{2}{|c|}{$11-15$} & \multicolumn{2}{|c|}{$11-15$} & \multicolumn{2}{|c|}{$11-15$} & & \\
\hline \multicolumn{8}{|l|}{ Sex } & \\
\hline Male & 119 & 58 & 118 & 48.8 & 167 & 42.2 & \multirow{2}{*}{13.739} & \multirow{2}{*}{$0.001^{* *}$} \\
\hline Female & 86 & 42 & 124 & 51.2 & 229 & 57.8 & & \\
\hline \multicolumn{9}{|l|}{ Grade } \\
\hline $\begin{array}{l}\text { Primary (fifth } \\
\text { grade) }\end{array}$ & 13 & 6.3 & 26 & 10.7 & 84 & 21.2 & \multirow{5}{*}{190.253} & \multirow{5}{*}{$0.000 * *$} \\
\hline $\begin{array}{l}\text { Primary (sixth } \\
\text { grade) }\end{array}$ & 8 & 3.9 & 19 & 7.9 & 108 & 27.3 & & \\
\hline $\begin{array}{l}\text { Preparatory (first } \\
\text { grade) }\end{array}$ & 33 & 16.1 & 72 & 29.8 & 88 & 22.2 & & \\
\hline $\begin{array}{l}\text { Preparatory } \\
\text { (second grade) }\end{array}$ & 78 & 38 & 32 & 13.2 & 76 & 19.2 & & \\
\hline $\begin{array}{l}\text { Preparatory (third } \\
\text { grade) }\end{array}$ & 73 & 35.6 & 93 & 38.4 & 40 & 10.1 & & \\
\hline \multicolumn{9}{|l|}{ Birth order } \\
\hline Premier & 42 & 20.5 & 77 & 31.8 & 132 & 33.3 & \multirow{6}{*}{26.346} & \multirow{6}{*}{$0.003 * *$} \\
\hline Second & 41 & 20 & 55 & 22.7 & 70 & 17.7 & & \\
\hline Third & 39 & 19 & 54 & 22.3 & 82 & 20.7 & & \\
\hline Fourth & 35 & 17.1 & 20 & 8.3 & 47 & 11.9 & & \\
\hline Fifth & 31 & 15.1 & 27 & 11.2 & 36 & 9.1 & & \\
\hline More than fifth & 17 & 8.3 & 9 & 3.7 & 29 & 7.3 & & \\
\hline \multicolumn{9}{|l|}{ practice sport } \\
\hline Yes & 107 & 52.2 & 116 & 47.9 & 144 & 36.4 & \multirow{2}{*}{16.444} & \multirow{2}{*}{$0.000 * *$} \\
\hline No & 98 & 47.8 & 126 & 52.1 & 252 & 63.6 & & \\
\hline
\end{tabular}

** Mean there is statistically significant difference

Table 6: Relation between eating disorders among studied adolescents and their body mass index. $\quad(n=$ 843).

\begin{tabular}{|c|c|c|c|c|c|c|c|c|}
\hline \multirow{3}{*}{ Body mass index. } & \multicolumn{6}{|c|}{ Eating disorders } & \multirow{3}{*}{$\mathbf{X}^{2}$} & \multirow{3}{*}{ P. value } \\
\hline & \multicolumn{2}{|c|}{$\operatorname{Bulimia}(n=205)$} & \multicolumn{2}{|c|}{ Anorexia(n=242) } & \multicolumn{2}{|c|}{$\operatorname{Normal}(n=396)$} & & \\
\hline & No. & $\%$ & No. & $\%$ & No. & $\%$ & & \\
\hline Underweight & 30 & 14.6 & 89 & 36.8 & 193 & 48.7 & \multirow{4}{*}{199.86} & \multirow{4}{*}{$<0.001 * *$} \\
\hline Normal & 108 & 52.7 & 142 & 58.7 & 199 & 50.3 & & \\
\hline Over weight & 44 & 21.5 & 5 & 2.1 & 3 & 0.8 & & \\
\hline Obese & 23 & 11.2 & 6 & 2.5 & 1 & 0.3 & & \\
\hline
\end{tabular}

**Mean there is statistically significant difference 
Table (1): Illustrates distribution of studied sample according to their personal data. It was noticed that; more than half of the studied adolescents were female $(52.1 \%)$. Also it shows that $\mathbf{2 9 . 7 \%}$ of them were being first birth order.

Figure (1): Shows that more than three quarters of studied sample $(76.0 \%)$ had poor score of knowledge as regarding eating disorder. While less than one fifth of them $(19.3 \%)$ had good score of knowledge as regarding eating disorders.

Table(2): Explains the types of eating disorders among studied adolescents .It was observed that more than half $(53.0 \%)$ of the studied sample were had eating disorders, $54.1 \%$ of them had anorexia and $45.9 \%$ of them had bulimia.

Table (3): Demonstrates the body mass index among studied adolescents. It was observed that more than half of adolescents (53.2\%) were normal weight. While more than one third of them $(37,0)$ were underweight; and the minority of them $(3.6 \%)$ were obese.

Table (4): Illustrates that there is statistical significant relation between total score of knowledge among studied adolescents and their personal data $(\mathrm{P}=0.000)$. The poor knowledge score being more frequently among females57.1\%; while good knowledge score being more frequently among males $66 \%$. Also there are $63.2 \%$ of studied pupils who had poor knowledge score were not practicing sport, but $64.2 \%$ of studied pupils who had good knowledge score were practicing sport.

Table (5): Clears that there is statistical significant difference between types of eating disorders and adolescents' socio- demographic characteristics. There are $58.0 \%$ of studied adolescents who had bulimia were males. While $51.2 \%$ of adolescents who had anorexia were females. Also $38.0 \%$ of adolescents who had bulimia were in second grade of preparatory school, although $38.4 \%$ of adolescents who had anorexia were in third grade of preparatory school. In addition to this table shows that $52.2 \%$ of studied pupils who had bulimia were practicing sport.

Table (6): Presents that, there is statistical significant difference between eating disorders and BMI of the studied adolescents $(\mathrm{P}<0.001)$. There are $14.6 \%$ of adolescents who had bulimia were underweight, but $11.2 \%$ of them were being obese. While $58.7 \%$ of adolescents who had anorexia were being normal body weight, and $2.5 \%$ of them were being obese. Also $50.3 \%$ of adolescents who had normal eating habits were being normal body weight.

\section{Discussion}

The present study aimed to assess eating disorders among early adolescents. Eating disorders describe illnesses that are characterized by irregular eating habits and severe distress or concern about body weight or shape.

the present study Illustrated that more than half of the studied adolescents were females. This result agree with Nur Syuhada Zofiran (2011), who conducted study about " Relation between eating habits and a high Body Mass Index among Freshman Students ", who found that more than half of the study subjects were female students. As well as El Sayed, et al., (2015), in their study about " Influence of dietary habits of University Students on Body Mass Index, found that more than half of the study participants were female students.

As regarding adolescents' knowledge about eating disorders the present study demonstrate that more than three quarters of studied sample had poor score of knowledge as regarding eating disorder. While less than one fifth of them had good score of knowledge as regarding eating disorders. These results agreed with Torres-Mcghee, et.,al (2011), who studied about Knowledge of Eating Disorders Among Collegiate Administrators, and found that more than half of participates had poor score of knowledge as regarding eating disorder.

While this results disagree with Marcia \& Winer, (2014) who conducted study in knowledge and attitudes towards eating disorders of undergraduates nutrition majors at three Colorado Universities, Department of Food Science and Human Nutrition, who stated that students from the three schools have similar knowledge and attitudes, they scored higher for knowledge of eating disorders and their types (anorexia nervosa and bulimia nervosa).

As regard distribution of eating disorders among studied adolescents the present study observed that more than half of the studied sample were had eating disorders, more than half of them had anorexia and less than half of them had bulimia. This result in the same line with Pearson\& Carolyn, (2014), who found in their study about eating disorders onset in young girls, there more than half of participates suffered from eating disorders. This might be attributed to the high level of concern about body shape that is reinforced by ideas about perfectionism that considered thin-ideal body as a standard of feminine beauty. In recent studies in Egypt revealed that less than two thirds $(65.0 \%)$ of the patients attending the weight management centers in Tanta were complaining of eating disorders Eladawi, (2017).

On other hand, In Egypt, Fawzi, et al., (2010) detected that $11.2 \%$ of secondary schoolgirls in Sharkia Governorate had eating disorders. Also a previous study of 432 Jordanian schoolgirls found 
that one-third of the participants had eating disorders.(Mousa, et al., 2010).

Regarding body mass index among studied adolescents the present study cleared that more than half of adolescents had normal weight. While more than one third of them had underweight; and the minority of them had obese. These results agree with Mahmoud, (2018), who conducted study about the association between eating habits and body mass index among nursing students in Benha university, who stated that, the majority of students were in normal weight category, while about one fourth of them were in overweight category and the remnant were in underweight and obese categories. These results going in line with the similar studies; Ayranci, et al., (2010) \& Al-Muammar, et al., (2014), represented that, about half the students were within normal weight, while more than one fourth of them were underweight.

As well, Benazeera, (2014), explored that more than half of the students were of normal weight; more than one-fourth were underweight; and few percentage of them were overweight/obese students. This is consistent with Hemati, et al., (2014), who stated that, the overall prevalence of normal weight represents the majority of the students, and two fifth of them were overweight and underweight while fewer percentage of them was obese. On the other hand, these findings are disagree with Waweru, et al.,(2016), who demonstrated that, almost of students had normal weight but there is a reasonably high occurrence of overweight among the students.

Regarding Relation between total score of knowledge about eating disorders among studied adolescents and their personal data, this study found the poor knowledge score being more frequently among females, while good knowledge score being more frequently among males, this results contradicted with Marcia\& Winer (2014) who found in females were more likely to correctly identify of eating disorders than males.

Based on Relation between types of eating disorders and adolescents' personal data. The present study cleared that there is statistical significant difference between types of eating disorders and adolescents' personal data. There are more than half of studied adolescents who had bulimia were males. While slightly more than half of studied adolescents who had anorexia were females. These results agreed with Francoise, (2010) who conducted study in early attachment and eating disorders: A comparative study between anorexia nervosa and bulimia nervosa, found that the two main eating disorder categories were anorexia nervosa and bulimia nervosa. Twenty-six participants ( $41.9 \%)$ were currently suffering from bulimia nervosa and 36 females $(58.1 \%)$ from anorexia nervosa. The results of the current study revealed that more than one third of adolescents who had bulimia were in second grade of preparatory school, although more than one third of adolescents who had anorexia were in third grade of preparatory school. This means that eating disorders either anorexia or bulimia were high incidence in second and third grade of preparatory school, these result may associated with rapidly body growth and development in this stage as physically maturation and sexually developing as well as age of menarche in females. These results similar to Swanson, et al., (2011) who estimated that high incidence of eating disorders between the ages of 12 to 15 years.

In addition this study shows that more than half of studied adolescents who had bulimia were practicing sport. This result agree with Ackerman \&Nazem, (2012) who found in their studies that there are most significant traits between sports practice eating disorders, and reported that Adolescents who participate in high level competitive sports which involve intense training are particularly at risk and more than half of them had eating disorders. These result may attributed to most of adolescents were striving for an ideal body shape often driven by a desire for positive perceptions by others.

Regarding Relation between eating disorders among studied adolescents and their body mass index. The present study revealed that, there is statistical significant between eating disorders and BMI of studied adolescents $(\mathrm{P}<0.001)$. These finding similar to Wong,(2014); who conducted study about body satisfaction, emotional intelligence, and the development of disturbed eating: a survey of Taiwanese students, and also found significant differences between eating disorders and body mass index among participated students $(\mathrm{p}<0.001)$. Also there are less than one fifth of adolescents who had bulimia were underweight, but $11.2 \%$ of them were being obese. While more than half of adolescents who had anorexia were being normal body weight, and minority of them were being obese. Also half of adolescents who had normal eating habits were being normal body weight. These results contradicted with Wong,(2014); who stated that, the proportion of obese and overweight students with abnormal eating attitudes (21.4\%) was higher than of those among underweight and normal weight adolescents (13.5\%). In addition, this results disagreed with Eladawi,(2017), who found in their studies more than half of the obese individuals suffered from eating disorders. 


\section{Conclusion}

Based on the results of the current study, it stated that there are more than half of studied adolescents are suffering from eating disorders, that characterized by a disturbance in eating habits and behavior. As well as this study confirmed that most widely recognized eating disorders of adolescence and young childhood are anorexia nervosa and bulimia nervosa This study revealed the lack of knowledge about eating disorders among adolescents may considering the main factor for developing eating disorders among them.

\section{Recommendations}

Based on the results of the current study, it recommended that:

- Education program about eating disorders for preadolescents and adolescents to increase their awareness and encourage health eating habits.

- Education program about eating disorders for school nurses to recognize conditions of eating disorders among students.

- Health information about eating disorders should be introduced into the curriculum of the primary and preparatory schools to highlight some aspect of eating disorders as symptoms, warning signs and prevention.

- Moreover further studies can be carried out to explore factors affecting eating disorders and the relation between eating disorders and academic achievement among students.

\section{References}

1. Abebe, D., Lien, L., \& von Soest, T., (2012): The development of bulimic symptoms from adolescence to young adulthood in females and males: A population-based longitudinal cohort study. International Journal of Eating Disorders, 45, 737-745.

2. Ackerman \&Nazem, 2012; Disordered eating: Young women's search for control and connection. Journal of Child and Adolescent Psychiatric Nursing, 20(2), 96-106

3. Allen, K., Fursland, A., Raykos, B., Steele, A., Watson, H., \& Byrne, S., (2012): Motivationfocused treatment for eating disorders: A sequential trial of enhanced cognitive behaviour therapy with and without preceding motivationfocused therapy. European Eating Disorders Review, 20, 232-239

4. Al-Muammar, M., El-Shafie, M., \& Feroze S., (2014): Association between dietary habits and body mass index of adolescent females in intermediate schools in Riyadh, Saudi Arabia. EMHJ; (20):1.
5. Ayranci, U., Erenoglu, N., \& Son, O., (2010): Eating habits, lifestyle factors, and body weight status among Turkish private educational institution students. Nutrition; 26(7-8):772-8.

6. Baker, J., Thornton, L. M., Lichtenstein, P., \&Bulik, C., (2012): Pubertal development predicts eating behaviors in adolescence. International Journal of Eating Disorders, 45, 819-826. Eating Disorders and Adolescents: https://www.eatingdisorders.org.au/eatingdisorders/eating-disorders-children-teens-andolder-adults/eating-disorders-a-adolescents.

7. Benazeera, U., (2014): Association between eating habits and body mass index (bmi) of adolescents. Journal of Medical Science and Public Health.

8. Cano, S., Merkestein, M., Skibicka, K., Dickson, S., \& Adan, R., (2012): Role of Ghrelin in the Pathophysiology of Eating Disorders. CNS drugs, 26(4), 281-296. DOI: 10.2165/11599890-000000000-00000

9. Combs, J., Pearson, C., Zapolski, T., \& Smith, G., (2013): Preadolescent disordered eating predicts subsequent eating dysfunction. Journal of Pediatric Psychology, 38, 41-49.

10. Doyle, Rachel Gayle, (2011): "A Quantitative Analysis of an Eating Disorder Prevention Program" All Theses and Dissertations. Paper 2736.

11. Duluth, G., (2010): Cause \& Effect: Eating Disordershttp://www.teenink.com/hot_topics/he alth/article/276564/Cause-Effect-EatingDisorders/

12. Eladawi, N., (2017): Prevalence and Associated Factors of Eating Disorders in Weight Management Centers in Tanta, Department of Public Health and Community Medicine, Faculty of Medicine, Mansoura University, Mansoura 35516, Egypt

13. El Sayed, H., El-Shafei, M., \& Toprak, L., (2015): Influence of dietary habits of university students on body mass index (BMI) (a comparative study among Egypt and Saudi Arabia and turkey). Firat University Journal of Social Science; 25(2): 315-328.

14. Fawzi M., Haitham M., Hashim A., \& Nelly R., (2010): Prevalence of eating disorders in a sample of rural and urban secondary schoolgirls in Sharkia, Egypt. Curr Psychiatry;17:112.

15. Francoise, R., (2010): Early attachment and eating disorders: A comparative study between anorexia nervosa and bulimia nervosa, A dissertation Submitted to the School of Psychology of Edith Cowan University, Western Australia. 
16. Gagne, D., Von Holle, A., Brownley, K., Runfola, C., Hofmeier, S., Branch, K., \& Bulik, C., (2012): Eating disorder symptoms and weight and shape concerns in a large web-based convenience sample of women ages 50 and above: Results of the gender and body image (GABI) study. International Journal of Eating Disorders, 45(7), 832-844.

17. Hardman, P., \& Richards, P., (2000): The Eating Survey. Orem, UT: The Center for Change.

18. Hart L., Granillo M., Jorm A., \& Paxton S., (2011): Unmet need for treatment in the eating disorders: a systematic review of eating disorder specific treatment seeking among community cases. Clinical Psychology Reviews, 31(5):72735. doi: 10.1016/j.

19. Hemati, A., Moghadasi, M., \& Azizi, F., (2014): Association among lifestyle status and body mass index in Yasuj adolescents. Int.J.Curr.Res.Aca.Rev; (8):19-24.

20. Mahmoud, M., (2018): The Association between Eating Habits and Body Mass Index among nursing students in Benhauniveristy. DOI: 10.9790/1959-0603061426.

21. Marcia H., \& Winer, S., (2014): Knowledge and attitudes towards eating disorders of undergraduates nutrition majors at three Colorado Universities, Department of Food Science and Human Nutrition.

22. Melbye, E., \& Hansen, H., (2015): Child weight and parental feeding practices: a childresponsive model. Nutrition and Food Science, 45 (1), 174-188.

23. Mousa T., Al-Domi H., Mashal R., \& Jibril M., (2010): Eating disturbances among adolescent schoolgirls in Jordan. Appetite. ;54:196201.doi:10.1016/j.appet.2009.10.008.

24. Nur Syuhada Zofiran, M., Kartini, I., SitiSabariah, B., \& Ajau, D., (2011): The relationship between eating behaviours, body image and BMI status among adolescence age 13 to 17 years in Meru, Klang, Malaysia. Am. J. Food. Nutr;1(4): 185-192.

25. Onozaka, Y., Melbye, E L, \& Hansen, H. (2014). What if you stop and think about it? Nutrition logos and product selection behavior.

26. Pearson, C. M., Combs, J., \& Smith, G., (2010): A risk model for disordered eating in late elementary school boys. Psychology of Addictive Behaviors, 24, 696-704

27. Pearson, M., \& Carolyn, G., (2014): Eating Disorder Onset In Young Girls: A Longitudinal Trajectory Analysis, Lexington, Kentucky.

28. Rosen D., (2014): Identification and Management of Eating Disorders in Children and adolescents. Pediatrics.;126:1240-1253. Eating Disorders: Causes, Symptoms, Signs \& Treatment

Helphttps://www.eatingdisorderhope.com/infor mation/eating-disorder

29. Swanson S., Crow S., \& Le Grange D., (2011): Prevalence and correlates of eating disorders in adolescents: results from the national comorbidity survey replication adolescent supplement, Arch Gen Psychiatry.

30. Taha A., \& Marawan H., (2015): Sociobehavioral Determinants of Overweight and Obesity in Egyptian Primary School Children. J Child AdolescBehav 3: 236. doi: 10.4172/23754494.1000236

31. Tholking M., Mellowspring A., \& Girarg Eberle S., (2011). American Dietetic Association: Standards of Practice and Standards of Professional Performance for Registered Dietitians (Competent, Proficient, and Expert) in Disordered Eating and Eating Disorders (DE and ED). Journal of the American Dietetic Association;111(8):12411249

32. Torres-Mcghee, T., Leaver-Dunn, D., Green, J., Bishop, P., Leeper, J., \& Richardson, M., (2011): Knowledge of Eating Disorders Among Collegiate Administrators, Coaches, and Auxilliary Dancers. Perception Motor Skills, 112(3)

33. Waweru, W., \& Marete, O., (2016): Estimation of relationship between eating habits and body mass index of students in Mount Kenya University, Rwanda. Int J Community Med Public Health; 3(8): 2344-2354.

34. Wong, Y., (2014): Body satisfaction, emotional intelligence, and the development of disturbed eating: a survey of Taiwanese students. School of Nutrition, Chung Shan Medical University, Taiwan, ROC.

35. World Health Organization (WHO) (2017): Global health observatory data: obesity and overweight fact sheet.31-Payne, K.F.) 